\title{
Another Glenoid Measurements for Shoulder Surgery
}

\author{
Yeon-Seok Jeong, Jae-Kwang Yum ${ }^{\square}$, Jun-Seok Lee \\ Department of Orthopaedic Surgery, Sanggye Paik Hospital, Inje University School of Medicine, Seoul, Korea
}

Background: We analyzed the angle between the glenoid anterior surface and glenoid axis, the range of the glenoid apex and the location of the glenoid apex for assistance during shoulder surgery.

Methods: Sixty-two patients underwent a computed tomography of the shoulder with a proximal humerus fracture. In the range of the glenoid apex, the ratios of the distribution of triangles with a Constant anterior and posterior area of the glenoid were measured. The location of glenoid apex was confirmed as the percentage of the position with respect to the upper part of the glenoid with the center of the part, analyzed the angle between the glenoid anterior surface and glenoid axis was measured.

Results: The angle between the glenoid anterior surface and glenoid axis was $19.80^{\circ} \pm 3.88^{\circ}$. The location of the glenoid apex is $60.36 \% \pm 9.31 \%$, with the upper end of the glenoid as the reference. The range of the glenoid apex was $21.16 \% \pm 4.98 \%$. When the height of the glenoid becomes smaller, the range of the glenoid apex tends to become larger $(p=0.001)$ and the range of the glenoid apex becomes wider $(p=0.001)$ as the glenoid width narrows.

Conclusions: We believe the anatomical measurements of the glenoid will be helpful for a more accurate insertion in glenoid component. It is thought that more accurate insertion is possible if we can set other anatomical measurements using computed tomography imaging of the glenoid which can develop into the study of other anatomical measurements.

(Clin Shoulder Elbow 2018;21(4):179-185)

Key Words: Anatomical analysis; Computed tomography; Glenoid apex; Glenoid axis; Glenoid angles

\section{Introduction}

As the number of reverse total shoulder arthroplasty and total shoulder arthroplasty performed has been increasing, the glenoid is becoming increasingly more important and many methods for accurate fixation have been presented. ${ }^{1-5)}$ Kelly et al. ${ }^{6}$ proposed the ' $12 \mathrm{~mm}$ rule', stating that when inserting the glenoid component, screw placement in the location $12 \mathrm{~mm}$ above the inferior glenoid rim led to good results. Theopold et al. ${ }^{7)}$ reported that the accuracy of glenoid component insertion can be improved by navigation based on three-dimensional (3D) images after insertion of the guide wire into the glenoid in the operation. In this way, many studies of fixation of glenoid implants have been conducted because it is known that there is a high incidence of glenoid bone loss and the glenoid fixation position has an important result on the glenoid component. If fixation of the glenoid component is not properly fixation, it gives rise to problems such as failure of initial fixation of the glenoid component, instability, and scapula notching., ${ }^{1,7-10)}$ This is due to the fact that the exposure of the glenoid cavity is a rather difficult technique and the scapula has a complex anatomical shape. ${ }^{1,711)}$ In order to improve the accuracy of glenoid component insertion in shoulder arthroplasty, techniques, such as navigation and patient-specific guide or instrumentation have been introduced. ${ }^{11-16)}$ It is difficult to set the position and orientation of the glenoid component without navigation or special equipment, but many shoulder surgeons perform surgery without such equipment. The aim of this study was to investigate anatomical landmarks of the glenoid cavity and scapula which have not been studied to date but can be used as reference points

Received June 1, 2018. Revised July 27, 2018. Accepted July 30, 2018.

Correspondence to: Jae-Kwang Yum

Department of Orthopaedic Surgery, Inje University Sanggye Paik Hospital, 1342 Dongil-ro, Nowon-gu, Seoul 01757, Korea

Tel: +82-2-950-1027, Fax: +82-2-950-1429, E-mail: Yumccf@hanmail.net, ORCID: https://orcid.org/0000-0002-0286-7981

IRB approval: Inje University Sanggye Paik Hospital (SGPAIK 2018-06-012).

Financial support: None. Conflict of interests: None. 
for shoulder surgery by 3D computed tomography (3D-CT) performed in the Inje University Sanggye Paik Hospital.

\section{Methods}

\section{Methods}

We studied 70 patients who underwent CT of the shoulder for proximal humerus fractures from January 2016 to December 2017. Among them, a total of 8 patients, including 6 patients with shoulder arthritis and 2 patients with glenoid fractures, were excluded from this study. Thus, a total of 62 patients and 62 shoulder joints were included in this study. The subjects consisted of 13 males and 49 females, and they were divided into two groups, Group A of those aged 30 to 70 years and Group $\mathrm{B}$ of those aged 71 years or over, to examine the differences according to gender and age. The mean age of the patients was 68.5 years (median: 70 years; range: 30-95 years). Thirty-five

Table 1. Demographic

\begin{tabular}{|cc}
\hline \multicolumn{1}{c}{ Variable } & Data \\
\hline Age $(\mathrm{yr})$ & $68.5(70,30-95)$ \\
\hline Orientation & 35 \\
\hline Right & 27 \\
\hline Left & \\
\hline Sex & 13 \\
\hline Male & 49 \\
\hline Female & $-2.08 \pm 1.28$ \\
\hline Body mass index $\left(\mathrm{kg} / \mathrm{m}^{2}\right)$ & $-2.35 \pm 0.69$ \\
\hline Lumbar & $165.60 \pm 8.35(160-174)$ \\
\hline Femur & $59.30 \pm 4.30(50-76)$ \\
\hline Height $(\mathrm{cm})$ & \\
\hline Weight $(\mathrm{kg})$ & \\
\hline
\end{tabular}

Values are presented as mean (median, range), number only, or mean \pm standard deviation (range). right shoulders and 27 left shoulders were studied (Table 1).

\section{Evaluation Items}

All the patients underwent 3D-CT (Aquilion One; Toshiba, Tokyo, Japan), and analysis for major anatomical landmarks of the glenoid cavity was conducted using the picture archiving and communication system (PACS, PiViewSTAR 5.0; INFINITT, Seoul, Korea). The glenoid width, glenoid height, glenoid anterior surface angle, glenoid apex location, and glenoid apex range were measured. Glenoid width was measured at the portion with the largest width in the axial plane of a CT-scan, and glenoid height was measured at the portion with the largest height in the coronal plane (Fig. 1). Glenoid apex location was identified in the sagittal plane and coronal plane based on the position where the anterior and posterior portions divided by the glenoid axis in the axial plane have the same area using the threedimensional analysis tool (Fig. 2, 3). The glenoid anterior surface angle was defined as the angle between the anterior surface of

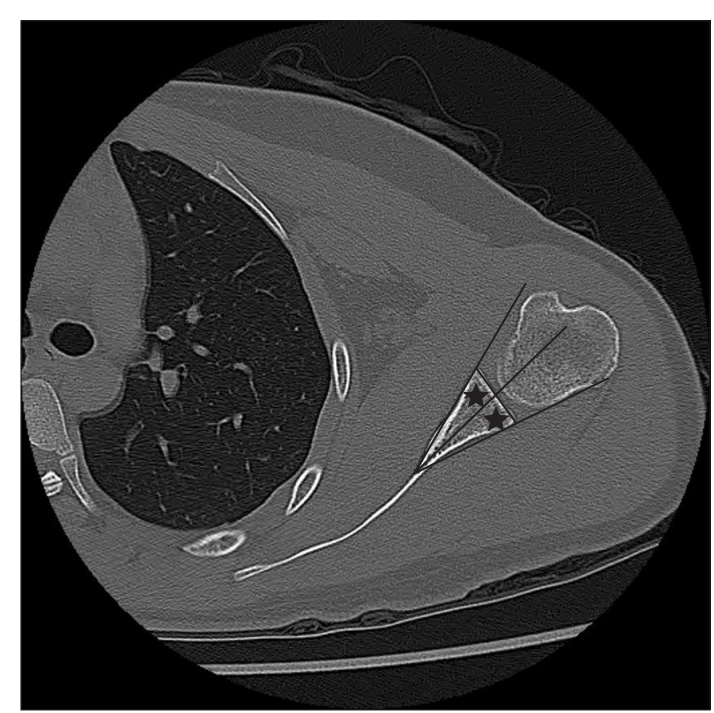

Fig. 2. The point of where anterior area and posterior area, along the glenoid axis, are similar on the axial plane (asterisks).

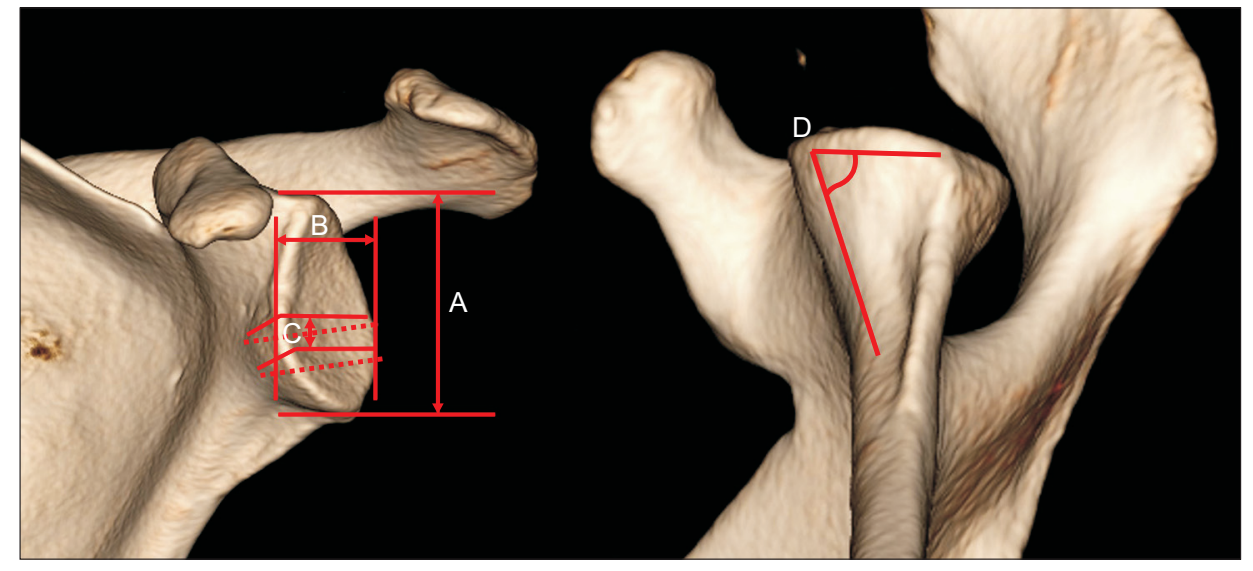

Fig. 1. Measurement of glenoid. A: glenoid height, B: glenoid width, C: glenoid apex range, D: glenoid anterior surface angle. 

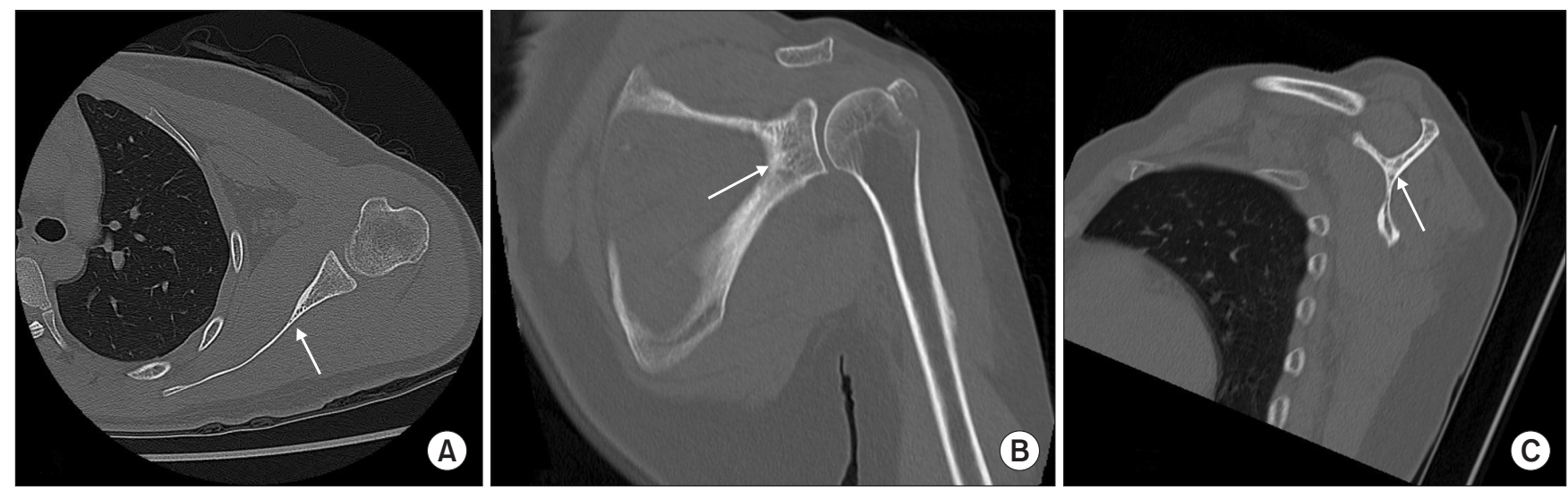

Fig. 3. Three-dimensional cursor tool for the apex of glenoid (arrows). First, in panel A, click on the apex of glenoid in axial plane. Panel B, C are the same level cut in coronal and sagittal plane.

the glenoid cavity and the glenoid axis at the location where the anterior and posterior portions, which are divided by the line drawn from the center of the glenoid surface to the glenoid apex in the axial plane (the glenoid axis), have the same area (Fig. 4). The glenoid apex range was measured as the range of the portion where the anterior and posterior lines transitioning from the glenoid neck to the glenoid articular surface with respect to the glenoid axis in the axial plane forms a straight line (Fig. 5A-C). The glenoid apex location was represented as the percentage from the superior portion of the glenoid at the location where the anterior and posterior portions divided by the glenoid axis in the axial plane have the same area (Fig. 5D). All measurements were performed by one shoulder specialist and one orthopedic resident.

\section{Statistical Analysis}

Statistical analysis was conducted using SPSS ver. 17.0 (SPSS Inc., Chicago, IL, USA), inter-observer reliability analysis was performed, and intraclass correlation coefficient (ICC) analysis was also conducted. The ICC value of 0.8 or more indicates an excellent level of reliability, $0.6-0.8$ indicates a good level of reliability, 0.4-0.6 indicates a fair level of reliability, and 0.4 or less indicates a poor level of reliability. The differences in the glenoid anterior surface angle according to gender and age were analyzed using Mann-Whitney U-test. The correlations among Glenoid apex range, glenoid apex location, and anatomical landmarks of the glenoid cavity were determined by Pearson correlation analysis. The level of statistical significance was set at $p<0.05$.

\section{Results}

The glenoid anterior surface angle was $19.80^{\circ} \pm 3.88^{\circ}$ $\left(15.80^{\circ}-28.90^{\circ}\right)$ for all the subjects, $19.92^{\circ} \pm 2.77^{\circ}\left(15.80^{\circ}-\right.$ $\left.26.40^{\circ}\right)$ for males and $19.76^{\circ} \pm 4.12^{\circ}\left(15.90^{\circ}-28.90^{\circ}\right)$ for

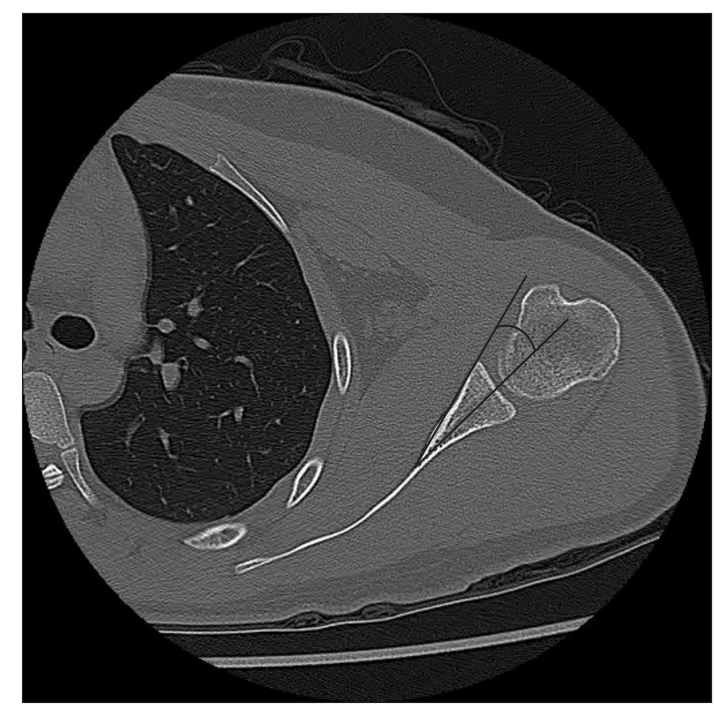

Fig. 4. Glenoid anterior surface angle. The angle between the glenoid axis and the glenoid anterior surface line, at which the anterior area and the posterior area are similar, was measured.

females, $20.57^{\circ} \pm 2.46^{\circ}\left(14.90^{\circ}-26.40^{\circ}\right)$ in Group $\mathrm{A}$, and $19.30^{\circ} \pm 4.75^{\circ}\left(12.00^{\circ}-31.00^{\circ}\right)$ in Group B, respectively. The glenoid apex location from the superior portion of the glenoid was $60.36 \% \pm 9.31 \%(45.05 \%-83.11 \%)$ for all the subjects, $54.69 \% \pm 8.62 \%(45.22 \%-75.78 \%)$ for males, $61.48 \% \pm$ $8.81 \%(45.05 \%-83.11 \%)$ for females, $58.25 \% \pm 10.16 \%$ (45.22\%-83.11\%) in Group A, and 62.48\% $\pm 7.23 \%(45.05 \%-$ $80.17 \%)$ in Group B. The glenoid height was $32.16 \pm 3.55$ $\mathrm{mm}(25.60-33.50 \mathrm{~mm})$ for all the subjects, $35.06 \pm 3.60 \mathrm{~mm}$ (30.54-43.50 mm) for males, $31.41 \pm 3.13 \mathrm{~mm}(26.42-41.67$ $\mathrm{mm}$ ) for females, $32.07 \pm 3.51 \mathrm{~mm}(25.48-43.50 \mathrm{~mm})$ for Group A, and $32.45 \pm 3.47 \mathrm{~mm}(25.87-41.67 \mathrm{~mm})$ for Group B. The glenoid width was $24.30 \pm 3.07 \mathrm{~mm}(18.65-36.14 \mathrm{~mm})$ for all the subjects, $26.71 \pm 1.85 \mathrm{~mm}(23.71-30.44 \mathrm{~mm})$ for males, $23.67 \pm 3.02 \mathrm{~mm}(18.65-36.14 \mathrm{~mm})$ for females, 25.04 

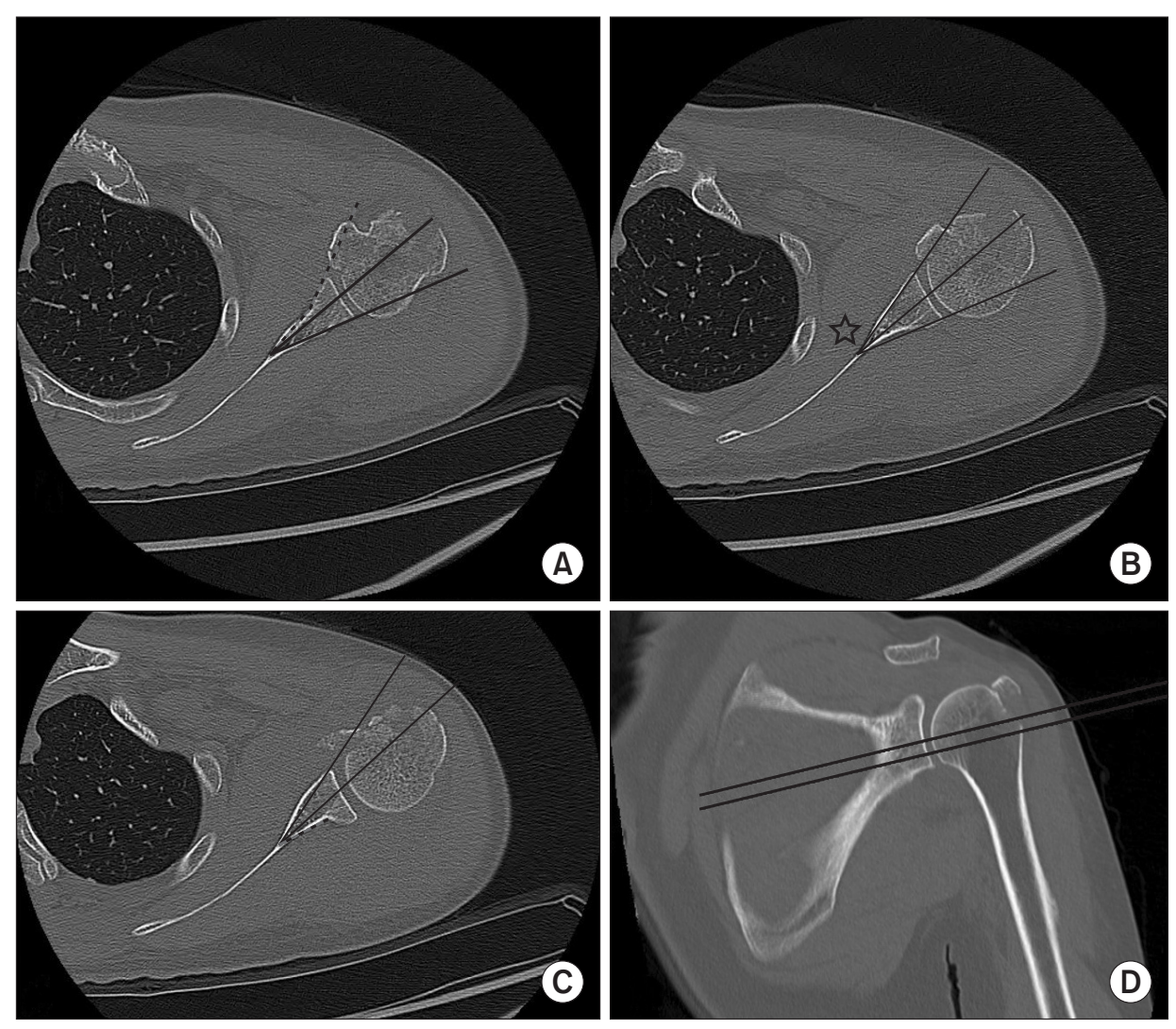

Fig. 5. (A) The anterior surface line (dotted line) of glenoid body and glenoid neck is not linear. (B) The point of where the anterior area and the posterior area along the glenoid axis are similar (asterisk). (C) The posterior surface line (dotted line) of glenoid body and glenoid neck is not linear. The anterior area and the posterior area along the glenoid axis are similar. The point where the anterior surface line and the posterior surface line meet was measured in this study. (D) The location from the glenoid upper margin to the point where the anterior surface line and the posterior surface line meet was divided by the total length of the glenoid height to calculate the percent ratio.

Table 2. Result of Glenoid Measurements (Sex)

\begin{tabular}{lcccc}
\multicolumn{1}{c}{ Variable } & \multicolumn{1}{c}{ Male } & Female & Total & p-value \\
\hline No. of patient & 13 & 49 & 62 & \\
Age $(\mathrm{yr})$ & $64.07 \pm 16.08(32-95)$ & $70.30 \pm 12.87(30-94)$ & $69.01 \pm 13.83(30-95)$ \\
\hline Glenoid height $(\mathrm{mm})$ & $35.06 \pm 3.60(30.54-43.50)$ & $31.41 \pm 3.13(26.42-41.67)$ & $32.16 \pm 3.55(25.60-33.50)$ & $0.04^{*}$ \\
\hline Glenoid width $(\mathrm{mm})$ & $26.71 \pm 1.85(23.71-30.44)$ & $23.67 \pm 3.02(18.65-36.14)$ & $24.30 \pm 3.07(18.65-36.14)$ & $0.01^{*}$ \\
\hline Glenoid anterior surface angle $\left(^{\circ}\right)$ & $19.92 \pm 2.77(15.80-26.40)$ & $19.76 \pm 4.12(15.90-28.90)$ & $19.80 \pm 3.88(15.80-28.90)$ & 0.89 \\
Gleonoid apex location $(\%)$ & $54.69 \pm 8.62(45.22-75.78)$ & $61.48 \pm 8.81(45.05-83.11)$ & $60.36 \pm 9.31(45.05-83.11)$ & $0.011^{*}$ \\
\hline Glenoid apex range $(\%)$ & $21.49 \pm 5.17(12.85-39.90)$ & $19.83 \pm 3.41(15.19-26.19)$ & $21.16 \pm 4.98(12.85-39.91)$ & 0.20 \\
\hline
\end{tabular}

Values are presented as number only or mean \pm standard deviation (range). Mann-Whitney test.

${ }^{\star}$ Statistically significant.

$\pm 2.25 \mathrm{~mm}(21.02-30.44 \mathrm{~mm})$ for Group A, and $23.84 \pm 3.52$ $\mathrm{mm}$ (12.59-36.14 mm) for Group B. The ICC was 0.93 for the glenoid anterior surface angle, 0.93 for the glenoid apex location, and 0.85 for the glenoid apex range, and the analysis was performed using the mean values of measures of two observers (Table 2, 3, Fig. 6).

There were statistically significant gender differences in glenoid height $(p=0.04)$, glenoid width $(p=0.01)$, and glenoid apex location $(p=0.011)$. There was no statistically significant difference in glenoid landmarks between the group of patients aged less than 71 years and the group of patients aged 71 years or over. There was no statistically significant differences in gle- noid anterior surface angle $(p=0.89)$ and glenoid apex range $(p=0.20)$. In addition, glenoid height and glenoid apex range had a statistically significant negative correlation $(p=0.001)$ with a Pearson correlation coefficient of -0.532 , but there was no significant correlation between glenoid height and glenoid apex location $(p=0.401)$. There was a statistically significant negative correlation between glenoid width and glenoid apex range with a Pearson correlation coefficient of $-0.442(p=0.001)$, and there was also a statistically significant negative correlation between glenoid width and glenoid apex location with a Pearson correlation coefficient of $-0.280(p=0.028)$. Glenoid anterior surface angle was not significantly correlated with glenoid apex location 
Table 3. Result of Glenoid Measurements (Age)

\begin{tabular}{lccc}
\hline \multicolumn{1}{c}{ Variable } & Group A (30-70 years) & Gorup B (71 years or over) & $p$-value \\
\hline No. of patient & 32 & 30 & $79.47 \pm 6.55$ \\
\hline Age $(\mathrm{yr})$ & $58.47 \pm 11.15$ & $32.45 \pm 3.47(25.87-41.67)$ & 0.068 \\
\hline Glenoid height $(\mathrm{mm})$ & $32.07 \pm 3.51(25.48-43.50)$ & $23.84 \pm 3.52(12.59-36.14)$ & 0.844 \\
\hline Glenoid width $(\mathrm{mm})$ & $25.04 \pm 2.25(21.02-30.44)$ & $19.30 \pm 4.75(12.00-31.00)$ & 0.462 \\
\hline Glenoid anterior surface angle $\left(^{\circ}\right)$ & $20.57 \pm 2.46(14.90-26.40)$ & $62.48 \pm 7.23(45.05-80.17)$ & 0.083 \\
\hline Gleonoid apex location $(\%)$ & $58.25 \pm 10.16(45.22-83.11)$ & $21.58 \pm 4.42(12.85-34.29)$ \\
\hline Glenoid apex range $(\%)$ & $20.17 \pm 4.08(13.30-27.28)$ & 0.719 \\
\hline
\end{tabular}

Values are presented as number only or mean \pm standard deviation (range). Mann-Whitney test.

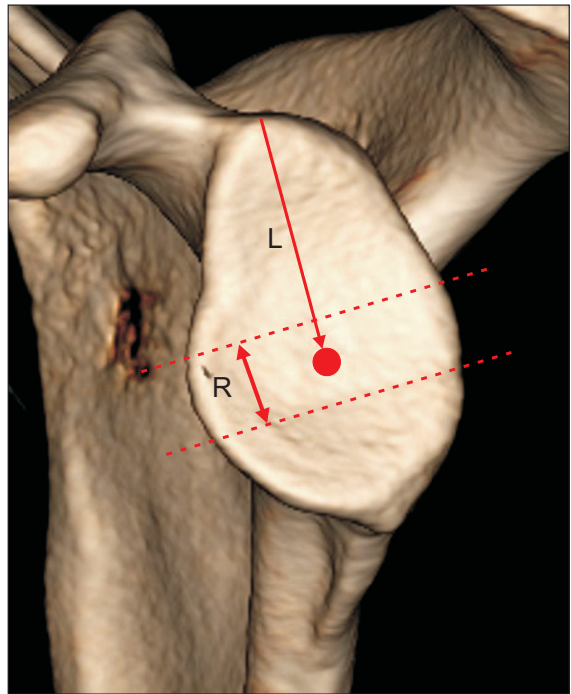

Fig. 6. The location of glenoid apex (L) is 60.36\%, the range of glenoid apex (R) is $21.16 \%$ (circle).

or glenoid apex range $(p=0.092,0.713)$ (Table 4$)$. As glenoid height decreased, glenoid apex range tended to increase. There was also a tendency that as glenoid width became smaller, glenoid apex range was increased and glenoid apex location became higher.

\section{Discussion}

The scapula and glenoid cavity are anatomically complex and there are gender differences in the shape. Regarding anatomical landmarks of the glenoid cavity, it has been reported that the mean glenoid width is $26.8 \mathrm{~mm}$ ( $20-35 \mathrm{~mm}$ ) and the difference between men and women is $4.2 \mathrm{~mm}$ on average. ${ }^{17-20)}$ It has also been reported that the mean glenoid height is $38.0 \mathrm{~mm}$ (29.4$50.1 \mathrm{~mm}$ ), and the mean difference between men and women is $4.7 \mathrm{~mm} .{ }^{17-20)}$ The differences between these values and the analysis results of anatomic landmarks in this study are almost similar to the disparities in the anatomic landmarks between North American and East Asian populations presented by Cabe-
Table 4. Statistical Analysis of Glenoid Apex (Pearson Correlation Coefficient)

\begin{tabular}{lccc}
\hline \multicolumn{1}{c}{ Variable } & $\begin{array}{c}\text { Glenoid anterior } \\
\text { surface angle }\end{array}$ & $\begin{array}{c}\text { Gleonoid } \\
\text { width }\end{array}$ & $\begin{array}{c}\text { Glenoid } \\
\text { height }\end{array}$ \\
\hline Gleonoid apex location & 0.092 & $0.028^{*}$ & 0.401 \\
Glenoid apex range & 0.713 & $0.001^{*}$ & $0.001^{*}$ \\
\hline
\end{tabular}

*Statistically significant.

zas et al. ${ }^{21)}$

Pinkas et al. ${ }^{19)}$ noted the importance of the glenoid vault of the cancellous bone surrounded by the thin cortical bone.In this study, it was found that as glenoid height became smaller, glenoid apex range was increased, and that as glenoid width became narrower, glenoid apex range was increased. These findings suggest that even if glenoid height is large, the portion of glenoid apex where the glenoid component can be safely inserted is small, so the glenoid component should be inserted carefully. As described above, we analyzed anatomical landmarks of the glenoid vault and found that the glenoid anterior surface angle is approximately $20^{\circ}$ on average, which is an important anatomical landmark to be used as a reference point when performing the insertion of the glenoid component.

The transitional part from the glenoid cavity to the body of the scapula is sharply narrowed. Thus, instability is likely to occur during the insertion of the glenoid component in shoulder arthroplasty, leading to failures of surgery. Gonzalez et al. ${ }^{22)}$ reported that $28.5 \%$ of shoulder arthroplasty requires the revision of the glenoid component. Therefore, many surgeons are now conducting research on the location for stable insertion of the glenoid component. According to Harman et al., ${ }^{23)}$ optimal positions for screw placement of the glenoid component can prevent the movement of the glenoid component in total shoulder arthroplasty, and ensure firm fixation of the glenoid component in reverse total shoulder arthroplasty. Verborgt et al. ${ }^{11)}$ showed that an improper position of the glenoid component may cause serious harm to the surrounding tissues such as axillary nerve, suprascapular nerve, rotator cuff muscles, and blood vessels. In this 
study, the glenoid apex range and location were analyzed as the landmarks which can be used as reference points regarding the specific location where the glenoid component could be safely positioned in the portion where the glenoid becomes narrower transitioning inward. It has been reported that the glenoid cavity usually has a pear shape but $29 \%$ appear elliptical. ${ }^{20)}$ Depending on these diverse shapes, glenoid apex range comprised $21 \%$ of glenoid height on average at the position of $60 \%$ of the superior portion of the glenoid cavity on average. This apex is the part where the anterior and posterior parts divided by the glenoid axis have the same area. If the glenoid component is positioned with reference to this position, it will be possible to obtain stable and firm fixation. Currently, various techniques for accurate insertion of the glenoid component such as navigation have been presented. Navigation is certainly helpful for correct insertion, but it has the drawback of increasing operative time and requiring an additional technical skill. ${ }^{24)}$

This study has some limitations. First, because the subjects were fracture patients, the numbers of male and female patients were different, so there was a possibility of gender bias. In addition, the number of the subjects was relatively low and they were limited to elderly patients.

\section{Conclusion}

When actually inserting the glenoid component into the glenoid cavity, it is difficult to determine the insertion position and orientation when there is no special equipment. It is thought that identification of the glenoid anterior surface angle, glenoid apex location and glenoid apex range by CT scan of the glenoid cavity will enable accurate fixation of the glenoid component.

\section{References}

1. Hart ND, Clark JC, Wade Krause FR, Kissenberth MJ, Bragg WE, Hawkins RJ. Glenoid screw position in the Encore Reverse Shoulder Prosthesis: an anatomic dissection study of screw relationship to surrounding structures. J Shoulder Elbow Surg. 2013;22(6):814-20.

2. Nyffeler RW, Werner CM, Gerber C. Biomechanical relevance of glenoid component positioning in the reverse Delta III total shoulder prosthesis. J Shoulder Elbow Surg. 2005;14(5):524-8.

3. Stephens BF, Hebert CT, Azar FM, Mihalko WM, Throckmorton TW. Optimal baseplate rotational alignment for lockingscrew fixation in reverse total shoulder arthroplasty: a threedimensional computer-aided design study. J Shoulder Elbow Surg. 2015;24(9):1367-71.

4. Parsons BO, Gruson Kl, Accousti KJ, Klug RA, Flatow EL. Optimal rotation and screw positioning for initial glenosphere baseplate fixation in reverse shoulder arthroplasty. J Shoulder Elbow Surg. 2009;18(6):886-91.
5. DiStefano JG, Park AY, Nguyen TQ, Diederichs G, Buckley JM, Montgomery WH 3rd. Optimal screw placement for base plate fixation in reverse total shoulder arthroplasty. J Shoulder Elbow Surg. 2011;20(3):467-76.

6. Kelly JD 2nd, Humphrey CS, Norris TR. Optimizing glenosphere position and fixation in reverse shoulder arthroplasty, part one: the twelve-mm rule. J Shoulder Elbow Surg. 2008; 17(4):589-94.

7. Theopold J, Pieroh P, Scharge ML, et al. Improved accuracy of K-wire positioning into the glenoid vault by intraoperative 3D image intensifier-based navigation for the glenoid component in shoulder arthroplasty. Orthop Traumatol Surg Res. 2016; 102(5):575-81.

8. Humphrey CS, Kelly JD 2nd, Norris TR. Optimizing glenosphere position and fixation in reverse shoulder arthroplasty, part two: the three-column concept. J Shoulder Elbow Surg. 2008;17(4):595-601.

9. Codsi MJ, lannotti JP. The effect of screw position on the initial fixation of a reverse total shoulder prosthesis in a glenoid with a cavitary bone defect. J Shoulder Elbow Surg. 2008;17(3): 479-86.

10. Matsen FA 3rd, Boileau P, Walch G, Gerber C, Bicknell RT. The reverse total shoulder arthroplasty. J Bone Joint Surg Am. 2007;89(3):660-7.

11. Verborgt O, De Smedt T, Vanhees M, Clockaerts S, Parizel PM, Van Glabbeek F. Accuracy of placement of the glenoid component in reversed shoulder arthroplasty with and without navigation. J Shoulder Elbow Surg. 2011;20(1):21-6.

12. Lewis GS, Bryce CD, Davison AC, Hollenbeak CS, Piazza SJ, Armstrong AD. Location of the optimized centerline of the glenoid vault: a comparison of two operative techniques with use of three-dimensional computer modeling. J Bone Joint Surg Am. 2010;92(5):1188-94.

13. Nguyen D, Ferreira LM, Brownhill JR, et al. Improved accuracy of computer assisted glenoid implantation in total shoulder arthroplasty: an in-vitro randomized controlled trial. J Shoulder Elbow Surg. 2009;18(6):907-14.

14. Mulligan RP, Azar FM, Throckmorton TW. Is a generic targeting guide useful for glenoid component placement in shoulder arthroplasty? J Shoulder Elbow Surg. 2016;25(4):e90-5.

15. Verborgt O, Vanhees M, Heylen S, Hardy P, Declercq G, Bicknell R. Computer navigation and patient-specific instrumentation in shoulder arthroplasty. Sports Med Arthrosc Rev. 2014;22(4):e42-9.

16. Walch G, Vezeridis PS, Boileau P, Deransart P, Chaoui J. Threedimensional planning and use of patient-specific guides improve glenoid component position: an in vitro study. J Shoulder Elbow Surg. 2015;24(2):302-9.

17. von Schroeder HP, Kuiper SD, Botte MJ. Osseous anatomy of the scapula. Clin Orthop Relat Res. 2001;(383):131-9.

18. Ebraheim NA, Xu R, Haman SP, Miedler JD, Yeasting RA. 
Quantitative anatomy of the scapula. Am J Orthop (Belle Mead NJ). 2000;29(4):287-92.

19. Pinkas D, Wiater B, Wiater JM. The glenoid component in anatomic shoulder arthroplasty. J Am Acad Orthop Surg. 2015; 23(5):317-26.

20. Checroun AJ, Hawkins C, Kummer FJ, Zuckerman JD. Fit of current glenoid component designs: an anatomic cadaver study. J Shoulder Elbow Surg. 2002;11(6):614-7.

21. Cabezas AF, Krebes K, Hussey MM, et al. Morphologic variability of the shoulder between the populations of North American and East Asian. Clin Orthop Surg. 2016;8(3):280-7.

22. Gonzalez JF, Alami GB, Baque F, Walch G, Boileau P. Com- plications of unconstrained shoulder prostheses. J Shoulder Elbow Surg. 2011;20(4):666-82.

23. Harman M, Frankle M, Vasey M, Banks S. Initial glenoid component fixation in "reverse" total shoulder arthroplasty: a biomechanical evaluation. J Shoulder Elbow Surg. 2005;14(1 Suppl S):162S-7S.

24. Kircher J, Wiedemann M, Magosch P, Lichtenberg S, Habermeyer P. Improved accuracy of glenoid positioning in total shoulder arthroplasty with intraoperative navigation: a prospective-randomized clinical study. J Shoulder Elbow Surg. 2009;18(4):515-20. 